\title{
KONTRIBUSI PENELITIAN FILOLOGI TERHADAP PERKEMBANGAN STUDI KEISLAMAN
}

\author{
Arif Ibrahim ${ }^{1}$, Ade Kosasih', Undang Ahmad Darsa ${ }^{3}$, Titin Nurhayati Ma'mun ${ }^{4}$ \\ Program Pascasarjana Fakultas Ilmu Budaya, Universitas Padjadjaran ${ }^{1234}$ \\ Email: baimrogers@gmail.com
}

\begin{abstract}
This article titled "The Contribution of Philology Research for Islamic Studeis Development. "This study aims to reveal the usefulness of a philological study which is Islamic nuance for Islamic studies development in Archipelago. This research uses descriptive analytical method and the scope of this study is the contribution of old Islamic manuscript for modern Islamic studies. The result of this study indicates that philology research with Islamic manuscript object reveals many aspects of religion, such as theology, jurisprudence, and tasawwuf. The author presents three researches that prove the philology's contribution for Islamic studies, they are the dissertation of Syarah Nashoihul 'Ibad in Banten and two theses namely Fiqih script of Sunda Islami in Kuningan and the At-Tariqah Al-Wadihah Ila Asrari Al-Fatihah's Text of Al-Fatihah.
\end{abstract}

Keywords: Contribution; Philology; Islamic Studies.

\section{Intisari}

Artikel ini berjudul "Kontribusi Penelitian Filologi Terhadap Pengembangan Studi Keislaman”. Penelitian ini bertujuan untuk mengungkap kegunaan sebuah penelitian filologi yang bernaskah islami terhadap perkembangan studi keislaman Nusantara. Anlisis ini menggunakan metode deskriptif analitik dan Ruang lingkup penelitian ini adalah kontribusi naskah-naskah lama islami terhadap studi keislaman saat ini. Hasil penelitian ini menunjukan bahwa penelitian filologi dengan objek naskah islami banyak mengungkap aspek-aspek keagamaan baik itu teologi, fiqih, dan tasawwuf. Penulis menampilkan tiga penelitian yang membuktikan kontribusi filologi terhadap studi keislaman, diantaranya disertasi Syarah Nashaihul 'Ibad di Banten dan dua tesis yaitu naskah fiqih sunda islami di Kuningan dan Naskah At-Tariqah Al-Wadihah Ila Asrari Al-Fatihah tentang tafsir surat AlFatihah.

Kata Kunci: Kontribusi; Filologi; Studi Keislaman

\section{Pendahuluan}

Tujuan akhir dari sebuah disipilin ilmu adalah melahirkan teori dalam tingkat keumuman yang tinggi. Sebuah teori dapat dimanfaatkan untuk memahami disiplin yang berbeda, sehingga dianggap pasti apabila suatu ilmu berkolerasi dengan ilmu lainnya. Begitupun dengan filologi yang memliki hubungan dengan beberapa ilmu lainnya.

Hubungan tersebut bersifat timbal balik yang artinya suatu ilmu berkontibusi 
pada filologi atau mendapat kontribusi dari filologi. Kemandirian suatu ilmu secara terperinci, hampir tidak bisa terjadi. Kolerasi antara satu ilmu dengan ilmu lainnya menjadi hal yang menarik untuk diungkap, pasalnya selain mengungkap fakta mengenai sebuah ilmu, disiplin ilmu yang lain akan ikut terungkap.

Di samping itu, mengetahui kolerasi antar ilmu dapat menambah referensi dan kemudahan dalam mengarungi sebuah ilmu, seperti halnya dengan studi keislaman. Studi keislaman Nusantara akan sangat terbantu dengan adanya berbagai referensi keislaman yang dihasilkan dari penelitian bidang lain yang berhubungan seperti filologi. Apapun yang terkait dengan islam pasti akan merujuk teks.

Teks pertama dalam islam adalah AlQuran dan Hadis. Sedangkan teks kedua adalah pemahaman umat muslim terhadap teks pertama. Teks kedua pun akan melahirkan teks ketiga, yaitu teks yang dipahami dari teks kedua dan seterusnya (Lutfi, 2016: 115). Hal itu menunjukan bahwa islam tidak bisa lepas dari teks yang berarti juga tidak bisa terlepas dari dunia filologi yang memiliki sasaran dan objek kerja berupa naskah dan teks. Selain itu, penggalian bahasa juga merupakan suatu objek dalam kajian filologi (Kingsley, 2013: 3). Kandungan isi manuskrip Nusantara sangat luas dan tidak terbatas pada kesusastraan saja, tetapi mencakup berbagai bidang lain seperti agama, sejarah, hukum, politik kesultanan, resolusi konflik, adat istiadat, obat-obatan, teknik, dan lain-lain (Said, 2016: 203). Dengan demikian, karya-karya para ulama Nusantara dalam berbagai bidang keislaman akan terus terjaga otentitasnya dengan kajian filologi. Karya-kaya ulama Indonesia tersebut seperti Kyai Soleh Darat, Sunan Bonang, Syekh Hasyim Asy'ari dan K.H Ahmad Dahlan di tanah Jawa, Abdu Rauf Singkel, Nuruddin AlRaniri, Ahmad Khatib Al-Minangkabawi dan Abdu Somad Al-Palembani di Sumatra, Syaikh Yusuf Al-Makasari di Sulawesi dan masih banyak lagi.

Salah satu contoh karya yang masih banyak digunakan adalah kitab Risalah Ahlu Sunnah Wal Jamaah yang menerangkan tentang aswaja, kitab karya Syeikh Hasyim Asy'ari tersebut masih menjadi pelajaran wajib di berbagai Pesantren Nusantara. Syeikh Hasyim yang hidup pada 1287-1366 H karyanya bisa sampai kepada kita hingga abad ini yaitu 1440 H. Otentitas karya tersebut bisa terjaga dan sampai pada generasi berikutnya dengan kajian filologi, kita bisa saksikan betapa besar kontribusi kajian filologi terhadap keislaman Nusantara.

Dalam studi ilmu sosial, filologi dianggap sebagai disiplin yang kurang menarik pasalnya objek penelitian filologi adalah naskah-naskah kuno dan tidak trendi, sebagian intelektual berfikir bahwa tidak ada gunanya mempersoalkan hal yang sudah mati. Kenyataannya adalah bahwa hingga saat ini, keilmuan internasional masih merujuk pada tulisantulisan lama seperti tulisan ilmuan Yunani kuno misalnya Arsitoteles dan Plato. Para penemu mesin uap, telepon genggam, dan litrik juga hingga saat ini dikenang karena kontribusinya terhadap dunia meskipun telah lama meninggal. Hal tersebut sudah sangat jelas menegaskan bahwa kematian yang sesungguhnya adalah kebodohan. Oleh karena itu filologi telah berhasil menjaga otentitas teks-teks kuno tersebut hingga saat ini dan mampu berkontribusi dalam berbagai bidang diantaranya studi keislaman. Salah satu upaya cendikiawan islam dalam berdakwah dan menjaga ajaran islam adalah dengan menulis. Tak heran jika terdapat kurang lebih 5000 naskah keislaman di Nusantara yang telah berhasil dicatat oleh Ismail Husain dan masih terus bertambah (Barried, dkk, 1994: 16). 
Oleh karena itu, dengan penelitian filologilah kekayaan intelektual islam tersebut bisa diungkap dan dijaga serta diberdayakan demi pengembangan studi keislaman. Banyaknya naskah-naskah islam di Nusantara menjadikan pentingnya kontribusi filologi untuk menjaga karyakarya asli para intelektual islam Indonesia.

Penjagaan otentitas karya tersebut menjadi bukti kemajuan intelektual bangsa Indonesia sejak zaman dulu. Selain itu karya ulama Nusantara akan menjadi acuan dari berbagai kelompok yang ingin memecah belah Nusantara dengan isu-isu agama. Maka penelitian ini menjadi penting untuk diungkap dalam rangka menjabarkan kontribusi filologi dan studi keislaman Nusantara.

\section{Metode Penelitian}

Pada penelitian ini, penulis menggunakan metode deskriptif analitik. Metode deskriptif analitik dilakukan dengan cara mendeskripsikan fakta-fakta yang kemudian di susul dengan analisis. Metode ini akan berusaha menguraikan objek secara komprehensif. Fakta yang ada di dalam objek tidak hanya akan diuraikan, melainkan akan dianalisis secara mendalam. Penelitian ini bertujuan untuk mengungkap kegunaan sebuah penelitian filologi yang bernaskah islami terhadap perkembangan studi keislaman Nusantara.

\section{Hasil dan Pembahasan}

Terdapat kaitan erat antara bekas kerajaan islam dan kehadiran naskah kuno. Dalam sejarah Ulama Nusantara sebelum adanya penerbitan, karya ulama tersebut dapat dibaca melalui bentuk tulisan tangan (manuskrip) (El-Mawa, 2016: 60). Objek kajian filologi yang berupa naskah, tidak selalu ada dalam bentuk yang sama. Kandungan setiap naskah dipengaruhi oleh budaya setempat yang beraneka ragam. Budaya tersebut mendorong adanya naskah dalam berbagai aksara, bahasa, dan sastra.

Keanekaragaman budaya inilah yang pada tahap pengkajiannya akan memberikan suatu kontribusi secara tidak langsung pada suatu bidang ilmu. Salah satu kontribusi yang dapat diberikan penelitian filologi adalah dalam studi keislaman. Berikut adalah beberapa naskah yang berkontribusi dalam perkembangan keislaman di Nusantara.

\subsection{Naskah Syarah Nashaihul 'ibad, Banten}

Naskah ini merupakah objek penelitian disertasi yang ditulis oleh Erdi Rujikartawi pada tahun 2015 di Program Pasca Sarjana Fakultas Ilmu Budaya Universitas Padjadjaran dengan judul "Syarah Nashaih Al-I'bad Syekh Nawawi Al-Bantani Dalam Pandangan Dan Sikap Masyarakat Pesantren Di Banten". Penelitian ini berfokus pada pandangan dan sikap masyarakat Pesantren terhadap kitab tersebut. Selain itu, penelitian ini juga meneliti pemikiran luhur Syekh Nawawi Al-Bantani sebagai pengarang, beliau merupakan salah satu ulama besar Nusantara asal Banten dan bahkan keilmuannya diakui di Mekah dan Madinah.

Kitab ini menjelaskan kitab Nashaih Al-I'bad karya Ibnu Hajar AlAsqolani. Secara umum, kitab ini sangat populer di kalangan Pesantren dan banyak digunakan dalam pengajian sehari-hari oleh para santri Bersama sang kyai. Kitab ini menjelaskan tentang nasihat-nasihat luhur dalam menjalankan kehidupan di Dunia agar mendapatkan kesuksesan di Akhirat. Adapun pemikiran Syeikh Nawawi Al-Bantani dalam kitab ini dibagi menjadi tiga poin utama, yaitu Aqidah, Muamalah, dan Akhlak. Salah satu pemikiran luhur beliau tentang Aqidah adalah: "Keimanan yang baik dapat menuntun manusia kepada ketakwaan, ketaatan, keikhlasan, zuhud, meninggalkan segala bentuk kemaksiatan, mempunyai rasa malu kepada Allah dan kepada sesama manusia, serta menjadi manusia yang sabar dalam menghadapi berbagai persoalan hidup". Dalam muamalah, beliau juga mempunyai pemikiran yang 
luhur seperti: "Seorang muslim sejati seharusnya menjaga keamanan dan ketentraman dari tangan dan lisannya, tidak menjadi orang yang takabbur, rakus dan hasud. Oleh karena itu, sifat tawadhu, qanaah, bersikap simpati dan santun serta memberikan manfaat bagi orang lain, menjadi hal yang penting bagi seorang muslim dalam menjalankan kehidupan di masyarakat" (Rujikartawi, 2015: 275).

Pemikiran-pemikiran luhur ini akan terungkap dengan adanya pengkajian mendalam pada naskah dengan metode penelitian filologi. Maka secara tidak langsung filologi telah berkontribusi dan merestorasi kekayaan intelektual masyarakat Banten. Adapun pandangan dan sikap masyarakat Pesantren Banten adalah mencapai keberkahan di Dunia dan mendapatkan Surga Allah, tujuan ini adalah sikap hidup yang selalu dijalankan oleh masyarakat Banten.

Hal tersebut bisa diwujudkan dengan adanya ridha Allah dan cara mendapatkan keridhaan tersebut adalah dengan kebajikan dan sikap saling mengasihi antar sesama. Pemahaman tersebut didapatkan dari kitab Syarah Nashaih Al-I'bad. Selain itu, masyarakat Pesantren Banten mengkaji kitab Syarah Nashaih Al-I'bad berulangulang dan selalu memuliakan penulisnya. Menurut mereka, dengan memuliakan pengarang suatu kitab yang dikaji, maka pengetahuan tersebut akan bermanfaat.

Lalu terdapat respon kognitif, afektif, dan konatif dalam sikap masyarakat Pesantren Banten terhadap Syarah Nashaih Al-I'bad. Sifat kognitif ini terlihat dari kontinuitas pembelajaran kitab tersebut dan menjadi landasan dalam bertindak sehari-hari. Sifat afektif ini dapat difahami dari wawancara seorang informan yang mengatakan bahwa kitab Syarah Nashaih Al-I'bad meruapakan karya luhur yang berbentuk nasihat dan diamalkan seharihari, tidak ada respon dan stigma negatif terhadap kitab tersebut. Sifat konatif ini terlihat karena masyarakat Pesantren melakukan berbagai aktifitas berdasarkan hal yang mereka ketahui dan yakini, maka dalam beriman, bermuamalah, dan berakhlak mereka berpegang terhadap kitab tersebut.

Oleh karena itu, filologi membantu masyarakat dalam membangun spirit keislaman. Kontribusi filologi dalam hal ini telah memberikan naskah yang bersih dari kesalahan agar pemahaman keislaman tidak keliru dan dapat difahami dengan baik. Selain itu, isi kandungan yang ada juga diekploitasi secara komprehensif sehingga masyarakat dapat memahaminya lebih mudah.

\subsection{Naskah Fiqih Sunda Islami Kuningan}

Naskah ini merupakan objek penelitian tesis yang dilakukan oleh Leni Nur'aeni pada tahun 2013 di Program Pasca Sarjana Fakultas Ilmu Budaya Universitas Padjadjaran. Penelitian tersebut berjudul "Kitab Fiqih: Kajian Filologis Naskah Sunda Islami”.

Penelitian ini berfokus pada fungsi sosial naskah di kalangan masyarakat Kuningan. Naskah ini disalin oleh H. Syamsuri pada tanggal 2 Maret 1976 menggunakan bahasa Sunda dan aksara pegon. Naskah ini membahas mengenai ilmu fiqih yang membimbing umat muslim dalam menjalankan ibadah dengan tata cara yang benar.

Pada umumnya setiap kitab fiqih memiliki kekhasan dan bobot pembahasan masing-masing, ada yang menjelaskan secara singkat seperti kitab safinah dan ada juga yang Panjang lebar seperti AlRaudhoh. Naskah ini sendiri hanya membeberkan bab Thaharoh (tata cara bersuci), solat, puasa, dan haji. Secara pragmatis, naskah fiqih ini masih digunakan sebagai referensi dan pegangan masyarakat dalam beribadah sehari-hari (Nur'aeni, 2013: 135). Selain itu, naskah 
ini juga digunakan sebagai bahan ajar agar difahami lebih mendalam. Sistem penulisan pada naskah tersebut menggunakan sistem penulisan pada saat itu dan mengakibatkan adanya beberapa perbedaan sistem tulis dengan zaman sekarang. Hal tersebut membuat naskah yang asalnya fungsional menjadi nonfungsional.

Oleh karena itu, penelitian filologi hadir membantu menyelamatkan kandungan naskah sehingga dapat difahami dengan benar oleh masyarakat saat ini. Dalam hal ini, penelitian filologi sangat jelas memberikan kontribusi besar pada eksistensi sumber referensi keislaman. Penelitian filologi terbukti telah berhasil mengangkat sistem makna yang terkandung dalam naskah yang asalnya sukar difahami menjadi lebih mudah.

\subsection{Naskah At-tariqah Al-wadihah Ila Asrari Al-fatihah tentang tafsir surat Al-fatihah.}

Naskah ini merupakan naskah tunggal yang menggunakan aksara dan bahasa Arab. Naskah ini digunakan sebagai objek penelitian tesis oleh Firdaus bin Edi pada tahun 2015 di Program Pasca Sarjana Fakultas Ilmu Budaya Universitas Padjadjaran dengan judul "Naskah Attariqah Al-wadihah Ila Asrari Al-fatihah: Edisi Teks, Terjemahan dan Kajian Metodologi Tafsir Surat Al-Fatihah". Naskah ini ditulis menggunakan kaidah penulisan khat Riq'i dan Farisi. Kandungan naskah menjelaskan mengenai makna dan asrar (rahasia) surat AlFatihah, naskah ini terbagi menjadi dua bab, bab yang pertama memiliki dua pasal, yaitu membahas makna dan rahasia kalimat basmallah serta lafadz Allah dalam kalimat basmallah tersebut. Kemudian bab kedua memiliki empat pasal yang membahas mengenai keutamaan, rahasia, asma Allah, serta kandungan makna pada setiap ayat Al-Fatihah.

Pada penelitian ini didapati bahwa dalam naskah ini terdapat banyak penjelasan mengenai keutamaan- keutamaan surat Al-Fatihah sebagai obat untuk berbagai macam penyakit (Edi, 2015: 186). Selain itu, dijelaskan tata cara menggunakan surat Al-Fatihah untuk pengobatan tersebut. Dalam penelitian ini juga terdapat dua metodologi tafsir yang digunakan, pertama adalah tafsir AlMa'tsur, yaitu metodologi tafsir yang menggunakan Al-Qur'an, Hadist, riwayat sahabat dan Tabi' in sebagai penjelasannya. Kedua tafsir Al-ijmali yaitu metodologi tafsir yang mengemukakan makna global ayat.

Dalam hal ini kita dapat melihat bagaimana penelitian filologi mampu menguak asrar atau rahasia surat Alfatihah dan juga metodologi tafsir. Kontribusi dalam penelitian ini ternyata tidak hanya untuk studi keislaman yang berupa tafsir dan kandungan makna, namun juga untuk kalangan medis yang bisa dimanfaatkan menyembuhkan berbagai macam penyakit. Tiga penelitian ini merupakan indikasi kongkrit beberapa kontribusi penelitian filologi kepada studi keislaman, penelitian filologi berpeluang sangat besar memberikan kontribusi kepada studi keislaman Nusantara karena kekayaan naskah islam di Indonesia.

\section{Simpulan}

Dari uraian ini, dapat disimpulkan bahwa penelitian filologi berkontribusi besar terhadap kehidupan religi di berbagai daerah seperti Banten dan Kuningan. Filologi telah berhasil menjaga otentitas naskah syarah Nasoihul I'bad, fiqih sunda islami, dan tafsir surat al-fatihah serta menyuntingnya agar mudah dipahami oleh masyarakat pada masa sekarang.

Pemikiran luhur Syeikh Nawawi AlBantani mengenai bidang teologi dan akhlak masih dipegang teguh hingga saat ini oleh masyarakat dalam kehidupan sehari-hari. Lalu masyarakat Kuningan beribadah dengan landasan fiqih dari naskah fiqih sunda yang ada di kalangan masyarakat setempat. Begitu juga dengan terungkapnya tata cara pengobatan dengan 
doa dan surat Al-Fatihah. Semua hal itu merupakan kontribusi filologi dalam menyuguhkan teks kepada masyarakat untuk memudahkan mereka dalam kehidupan sehari-hari.

Terdapat beberapa penelitian yang mampu menepis anggapan keliru mengenai filologi. Artikel ini juga berupaya untuk membuktikan bahwa ada kontribusi besar dari penelitian filologi terhadap berbagai bidang ilmu, salah satunya studi keislaman. Dalam penelitian ini, penulis menemukan berbagai temuan-temuan baru dari objek filologi untuk studi keislaman. Penulis menyarankan agar penelitian ini dilanjutkan dengan meninjau kontribusi penelitian filologi terhadap berbagai disiplin ilmu yang lainnya.

\begin{tabular}{|c|c|c|c|}
\hline No & Penelitian & Keterangan & $\begin{array}{l}\text { Kontribusi Terhadap Studi } \\
\text { Keislaman }\end{array}$ \\
\hline 1 & $\begin{array}{l}\text { Disertasi Erdi } \\
\text { Rujikartawi } \\
\text { (2015): Naskah } \\
\text { Syarah } \\
\text { Nashaihul } \\
\text { 'ibad, Banten. }\end{array}$ & $\begin{array}{c}\text { Naskah merupakan } \\
\text { karangan Ulama } \\
\text { besar Nusantara asal } \\
\text { Banten, yaitu Syekh } \\
\text { Nawawi Al-Bantani. } \\
\text { Naskah ini } \\
\text { membahas mengenai } \\
\text { aqidah, muamalah, } \\
\text { dan akhlak. }\end{array}$ & $\begin{array}{l}\text { Pemikiran luhur Syekh } \\
\text { Nawawi mengenai akidah, } \\
\text { mua'amalah, dan akhlak } \\
\text { yang hingga saat ini } \\
\text { dipegang teguh oleh } \\
\text { masyarakat. }\end{array}$ \\
\hline 2 & $\begin{array}{l}\text { Tesis Leni } \\
\text { Nur'aeni } \\
\text { (2013): Naskah } \\
\text { Fiqih Sunda } \\
\text { Islami, } \\
\text { Kuningan. }\end{array}$ & $\begin{array}{c}\text { Naskah ini } \\
\text { menggunakan } \\
\text { bahasa sunda dengan } \\
\text { aksara pegon, } \\
\text { kandungan naskah } \\
\text { membahas mengenai } \\
\text { thaharah, solat, } \\
\text { puasa, dan haji. }\end{array}$ & $\begin{array}{c}\text { Penjelasan mengenai ilmu } \\
\text { fiqih yang meliputi thaharah, } \\
\text { solat, puasa, dan haji sebagai } \\
\text { pedoman masyarakat dalam } \\
\text { beribadah sehari-hari. }\end{array}$ \\
\hline 3 & $\begin{array}{c}\text { Tesis Firdaus } \\
\text { bin Edi (2015) } \\
\text { Naskah } \text { At- } \\
\text { tariqah } A l- \\
\text { wadihah Ila } \\
\text { Asrari } A l- \\
\text { fatihah tentang } \\
\text { tafsir surat Al- } \\
\text { fatihah }\end{array}$ & $\begin{array}{c}\text { Naskah ini } \\
\text { menggunakan aksara } \\
\text { dan bahasa Arab. } \\
\text { Kandungan naskah } \\
\text { membahas mengenai } \\
\text { makna dan asrar } \\
\text { (rahasia) surat Al- } \\
\text { Fatihah. }\end{array}$ & $\begin{array}{c}\text { Penjelasan mengenai } \\
\text { keutamaan-keutamaan surat } \\
\text { Al-Fatihah sebagai obat } \\
\text { untuk berbagai macam } \\
\text { penyakit dan tata cara } \\
\text { pengobatannya. }\end{array}$ \\
\hline
\end{tabular}

Tabel 1: Tabel beberapa penelitian filologi dan kontribusinya terhadap studi keislaman.

\section{Referensi}

Baried, Baroroh. dkk. (1994). Pengantar
Teori Filologi. Yogyakarta: BPPF.

Edi, bin Firdaus. (2015). "Naskah At tariqah Al-wadihah Ila Asrari Alfatihah:Edisi Teks, Terjemahan dan Kajian Metodologi Tafsir Surat AlFatihah" UNPAD, Jatinangor.

El-mawa, mahrus. (2016). "filologi

Nusantaradan Perpustakaan:Potret

Layanan Khusus Pengguna Studi

Islam Indonesia” Jurnal Kajian

Informasi dan Perpustakaan, IAIN

Syekh Nurjati Cirebon.

Hidayat, Syarif. (2002). Teologi Dalam

Naskah Sunda Islami. Bandung:

Sygma Kreative Corp.

Hidayatullah, Ave Elit jurnal. (2015).

"Studi Filologi Dunia Islam dan

Barat Dalam Menyelami Sejarah dan

Membangun Peradaban" Jurnal

Saintifika Islamica volume 2

no. 1

Kingsley, George. (2013). "The

Psycho-biology of Language:

an Introduction to Dynamic

Philology"

Lutfi, Habibi Muhammad. (2016).

"Kontekstualisasi Filologi dalam naskah-naskah Nusantara" Jurnal

IAIN Purwekerto, no. 14, 115.

Nur'aini, Leni. (2013). “Kitab Fiqih:

Kajian Filologis Naskah Sunda

Islami' 'UNPAD, Jatinangor.

Rujikartawi, Erdi. (2015). "Syarah

Nashaih Al-I'bad Syekh Nawawi Al-

Bantani Dalam Pandangan dan

Sikap Masyarakat Pesantren Di

Banten" UNPAD, Jatinangor.

Said, Nur. (2016). "Meneguhkan Islam

Harmoni Melalui Pendekatan

Filologi" Jurnal Ilmu Aqidah dan Studi Keagamaan Volume 4 Nomor 2 STAIN Kudus 